\title{
Solvent Extraction of Te(VII) by Calixarenes Bearing Pyridino Groups
}

\author{
Rainer Ludwig*,a and Nguyen Thi Kim Dzung ${ }^{a, b}$ \\ ${ }^{a}$ Freie University Berlin, Inst. of Chem./IAC, Fabeckstr. 34-36, 14195 Berlin, Germany \\ ${ }^{\mathrm{b}}$ ITRRE, Vietnam Atomic Energy Commission, 48 Lang Ha Street, Hanoi, Vietnam
}

\section{Received: July 31, 2005; In Final Form: September 30, 2005}

\begin{abstract}
The distribution of Tc(VII) between aqueous acidic solutions and organic solutions of nitrogen-containing extractants is investigated in order to establish the relationships between extraction power towards the Tc(VII)-anion, ligand molecular structure, influence of the media and the speciation in this ion-pair extraction. Ligands belonging to the class of calixarenes, derivatized with pyridino groups were newly devloped for these purposes. The number of substituents per calixarene, the position of the nitrogen and the size of calixarene are varying structural parameters. The nitrogen atoms are either protonated or quaternized to allow ion-pair extraction. The aqueous phase contains nitrate or chloride at varying or constant ionic strength. Experiments using Aliquat-336 were conducted under similar conditions.
\end{abstract}

\section{Introduction}

In the course of studies on coupled transport of Tc(VII) and $\mathrm{U}(\mathrm{VI})$ by conventional extractants such as $\mathrm{TBP}^{1}$, we realized the impact of anion competition and acid extraction on the separation of $\mathrm{Tc}$ (VII). Furthermore, we were interested whether macrocyclic ligands are able to extract $\mathrm{Tc}(\mathrm{VII})$ more selectively compared with non-cyclic or monodentate ligands. Among the latter, quaternary amines such as Aliquat-336 extract Tc(VII) well. ${ }^{2,3}$ An example for the macrocyclic effect with cooperative binding to the anion was recently observed with respect to $\mathrm{HPO}_{4}^{2-}$. $^{\circ}$

Among macrocyclic ligands, calixarenes ${ }^{5}$ gained significant interest in the field of ion recognition. So far, few publications on the extraction of Tc(VII) by nitrogen-containing crowned calixarenes were published, in which the relationship between ligand structure and binding was thoroughly investigated. ${ }^{6,7}$ Metalated cyclotriveratrylenes extract anionic Tc(VII) and $\mathrm{Re}(\mathrm{VII})$ as ion pairs, the selectivity over competing anions improves when the ligand has a deep cavity. ${ }^{8}$ Calix [4]arenes with carbonyl groups ${ }^{9}$ were reported to complex alkali ions and extract $\mathrm{Tc}(\mathrm{VII})$ as ion-pair at high $\mathrm{pH}$. Crowned calixerenes turned out to be effective in co-extracting $\mathrm{Tc}(\mathrm{VII})$ with $\mathrm{Cs}^{+}$as counterion from both acidic and alkaline media. ${ }^{10}$

In terms of this work we synthesized a series of calix[n]arenes $(\mathrm{n}=4,6,8)$ bearing methylpyridyl (picolyl) groups and investigated their ligating behaviour by means of solvent extraction from acidic media. The calixarene acts as molecular backbone to which the pyridino groups are anchored via methoxy groups in vicinity to each other. The purpose of the pyridino groups in protonated state is to provide an anion exchange functionality, and the possibility of backextraction by deprotonating them. The number of pyridino groups per molecule, the position of the nitrogen atom as well as the size and flexibility of the calixarene vary among the ligands in order to systematically study the influence of the molecular structure. In addition, ligands bearing quaternized pyridinium groups were synthesized. All these substituents were attached to the so-called 'lower rim' of the calixarene. In the distribution experiments, the concentration and kind of acid as well as the ionic strength were varied. Extraction by Aliquat $-3366^{\circledR}$ under the same conditions was done for reasons of comparison.

*Corresponding author. E-mail: rludwig@mail.chemie.fu-berlin.de. FAX: +49-30-838-52424.

\section{Experimental}

The structures of the extractants developed for this purpose are shown in Scheme 1. In addition to those, di- and tri-substituted 2 PyOC4 were investigated in terms of work. The abbreviation



Scheme 1. Extractants developed for this work. 
2PyOC4 for example means toctyl calix[4]arene functionalized with four 2-pyridyl methoxy groups. The compounds $2 \mathrm{PyOC} 4$, $4 \mathrm{PyOC}^{11}$ and $2 \mathrm{PyBuC}^{12}$ was reported previously. The synthesis of the other ligands involves treatment of the corresponding parent calix $[n]$ arene $(n=4,6,8)$ with a base, followed by reaction with picolylchlorides and work-up by crystallization or column chromatography, similar to References 13 and 14. Quaternization was done by reaction with methyliodide. The compounds were identified by ${ }^{1} \mathrm{H} /{ }^{13} \mathrm{C}-\mathrm{NMR}$, elemental analysis, MS and thin-layer chromatography. Their analytical data and the synthesis details will be reported elsewhere.

Solvent extraction was carried out batchwise in sealed PEvials at $295 \pm 2 \mathrm{~K}$ and equal phase volumes of $3 \mathrm{~mL}$. Magnetic stirring was carried out overnight. It has not been tested which time period is sufficient to reach equilibrium. In previous anion extraction ${ }^{15}$ it was two minutes, while in $\mathrm{Ag}(\mathrm{I})$ extraction a slow kinetics was observed. ${ }^{11}$ The organic phase contained $0.002 \mathrm{M}$ calixarene or $0.008 \mathrm{M}$ Aliquat-336 in chloroform. The aqueous phase contained $0.00005 \mathrm{M}^{99} \mathrm{Tc}\left(\mathrm{TcO}_{4}{ }^{-}\right)(3 \mathrm{kBq})$ and either nitrate or chloride: $\mathrm{HNO}_{3}(0.003$ to $4 \mathrm{M})$ or a mixture of $\mathrm{HNO}_{3}$ and $\mathrm{N}(\mathrm{Me})_{4} \mathrm{NO}_{3}\left(3 \mathrm{M} \mathrm{NO}_{3}^{-}\right)$; or $\mathrm{HCl}(0$ to $5 \mathrm{M})$. For weakly acidic solutions, the $\mathrm{pH}$ at equilibrium was measured with a glass electrode. One $\mathrm{mL}$ of the aqueous phase was subjected to liquid scintillation $\beta$-counting. The activity in the organic phase was calculated from the difference to the initial one.

\section{Results and Discussion}

Effect of substituent number. Figure la shows the distribution coefficients $\left(D=\mathrm{c}_{\mathrm{org}} / \mathrm{c}_{\mathrm{aq}}\right)$ for Tc(VII) in the extraction by calix[4] arenes bearing 2, 3, or 4 pyridino (py) substituents at the lower rim. In this series, the nitrogen atom is located ortho to the anchor group (2PyOC4), thus being located 'inside' the cavity. The extractability decreases when the nitric acid concentration increases, an effect which is discussed later.

There is a significant increase in $\log D$ when the number of py-groups changes from two to three. Introducing a fourth pygroup contributes little to the extractability. It is concluded that three nitrogen atoms are mainly involved in binding to $\mathrm{TcO}_{4}$ by means of ion-ion, cation-dipole and hydrogen bond interactions. The calix[4] arene backbone may be too rigid to allow the fourth nitrogen atom to rearrange into a position suitable for interaction.

Calix[6]arenes are characterized by a higher molecular flexibility and the possibility to introduce up to 6 functional groups. In Figure $1 b$, data for the 2PyOC6 are shown. In both Figures $1 \mathrm{~b}$ and $1 \mathrm{a}$, the nitrogen is located at ortho position. Results for nitrogen in 3-position (3PyBuC6 and 3PyOC6) are given in Figures 1c and 1d, respectively. However, the anchoring of 3, 4, or 6 py-groups does not significantly improve the extraction of $\mathrm{Tc}$ (VII) as compared with calix[4] arenes as seen in Figures $1 \mathrm{~b}$ to $1 d$. The extraction improves only slightly when more pygroups are contained within the molecule. The reasons may be (i) that the short methoxy spacers do not allow re-orientation of the py-groups according to an 'induced fit' mechanism, and (ii) entropy loss of the ligand during complexation. Data for the hexa-substituted tbutylcalix[6] arene are not included, because the ligand precipitates upon complete protonation. $t^{t}$ Octyl groups render the ligands sufficiently hydrophobic even in the protonated state and this was the reason why for this study the majority are ${ }^{t}$ octylcalixarenes.

Position of the nitrogen atom in the substituents. Figure 2 shows results for calix [4] arenes where the nitrogen atom in the py-groups is located at the 4-position (4PyOC6), 'outside' the cavity. As in Figure 1a, the values for $\log D$ are higher for the tetra-substituted ligand. Changing the acid concentration in the aqueous phase over a wider range shows two regions for the distribution coefficient: an increase at the weakly acidic
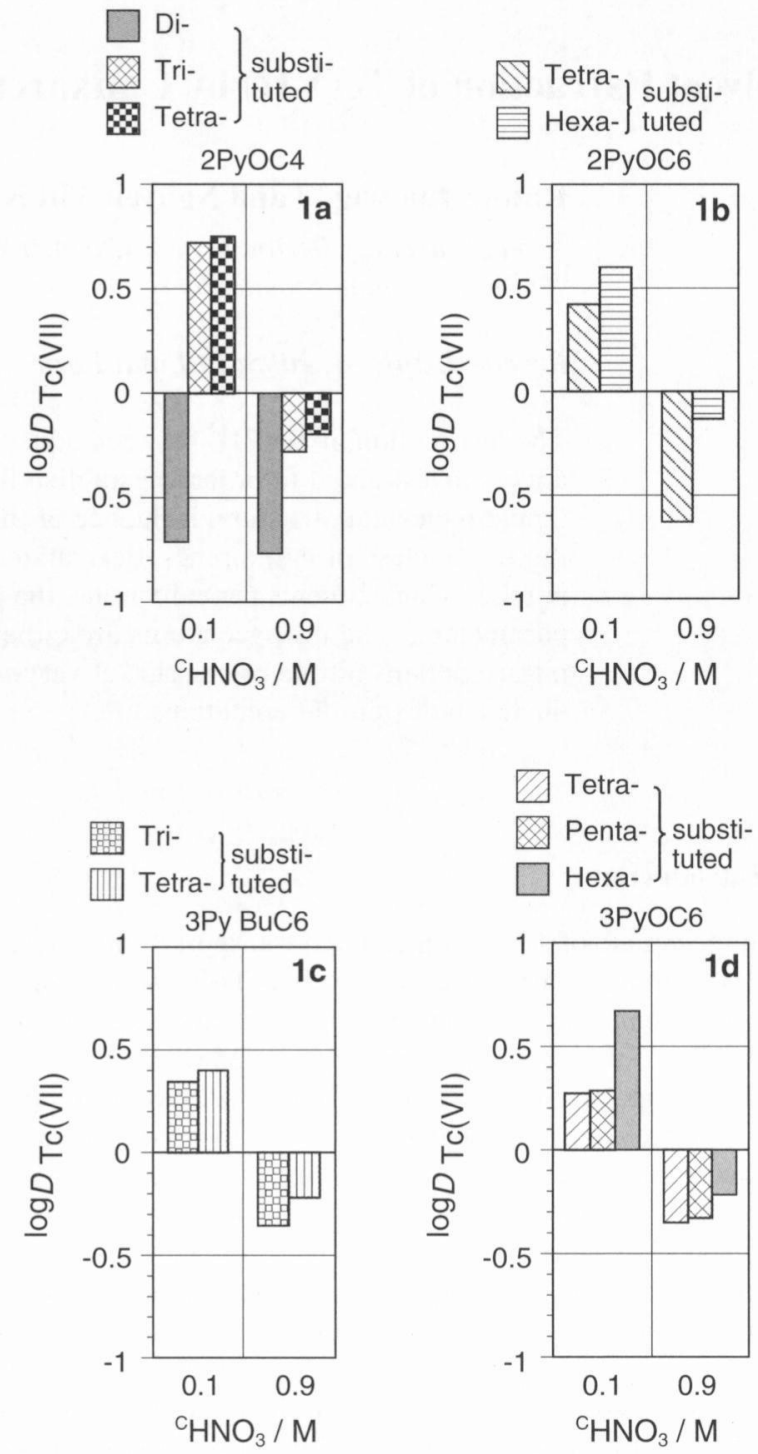

Figures 1. Effect of substituent number per calixarene on the distribution coefficient of Tc(VII): 2-Py groups on calix[n]arenes (1a: $n=$ 4, 1b: $n=6)$; 3-Py groups on ${ }^{t}$ butyl- (1c) and ${ }^{t}$ octylcalix[6]arene (1d). Aq. Phase: ${ }^{99} \mathrm{Tc}\left(\mathrm{TcO}_{4}^{-}\right) 0.05 \mathrm{mM}(3 \mathrm{kBq} / \mathrm{mL})$ in $\mathrm{HNO}_{3}(0.1$ or $0.9 \mathrm{M})$ Org. Phase: $2 \mathrm{mM}$ extractant in $\mathrm{CHCl}_{3}$. Tetra- (1a) and Hexa-substituted (1b, 1d) correspond to 2PyOC4, 2PyOC6 and 3PyOC6 respectively in Scheme 1.



Figure 2. Effect of nitric acid concentration on Tc(VII) extraction by di- and tetra-substituted calix [4] arene. Aq. Phase: ${ }^{99} \mathrm{Tc}\left(\mathrm{TcO}_{4}{ }^{-}\right) 0.05$ $\mathrm{mM}(3 \mathrm{kBq} / \mathrm{mL})$ in $\mathrm{HNO}_{3}$ (varying concentration); Org. Phase: $2 \mathrm{mM}$ extractant in $\mathrm{CHCl}_{3}$. 
region results from the protonation of the nitrogen atoms. Although the protonation constants were not yet measured, we assume that protonation occurs stepwise due to cooperativity, as does deprotonation in carboxylic acid derivatives. ${ }^{16,17}$ The distribution coefficient decreases at higher acidity nearly linearly on a half-logarithmic scale.

In Figures $3 \mathrm{a}$ and $3 \mathrm{~b}$ the position of the nitrogen atom, either ortho or para with respect to the anchor group (2PyOC4 and $4 \mathrm{PyOC} 4$, respectively) is compared for partially (3a) and fully substituted (3b) calix[4]arenes. We observe significant differences: In the di-substituted ligands, the protonation of the nitrogen dominates up to $0.3 \mathrm{M} \mathrm{HNO}_{3}$ and causes an increase in $\log D$. In tetra-substituted calixarene, the $2 \mathrm{PyOC} 4$ starts with high $\log D$-values, while $4 \mathrm{PyOC} 4$ first passes the protonation stage before it can extract $\mathrm{Tc}(\mathrm{VII})$. We interpret this difference in terms of a cooperative effect in $2 \mathrm{PyOC} 4$, which promotes protonation even at low acidity. On the other hand, 4PyOC4 offers the advantageous possibility of Tc-backextraction with diluted acid.

Figure 4 compares ortho- and meta-position of the nitrogen (2PyOC6 and 3PyOC6, respectively). As for the calix[4]arenes on the previous picture, in these calix[6]arenes the nitrogen in 2-position (ortho) appears to be protonated all over the investigated range. The 3 Py-derivative (meta position) lies in-between the ortho- and para ones, showing a region where it is not yet fully protonated $\left(<0.1 \mathrm{M} \mathrm{HNO}_{3}\right)$. We therefore conclude that
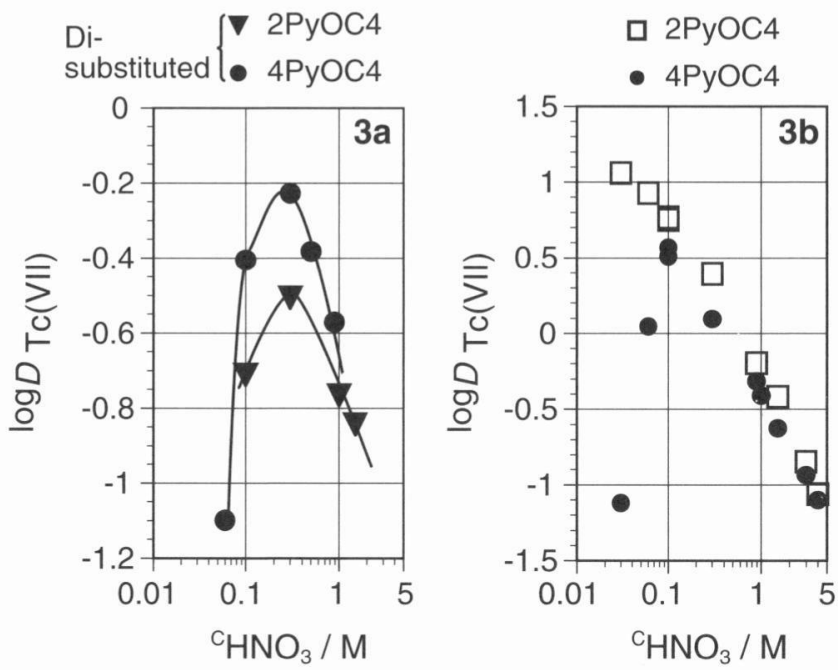

Figures 3. Influence of the position of nitrogen in the pyridino substituent on the extraction of Tc(VII). Left (3a): Disubstituted ligands; right (3b): fully substituted ligands. Aq. and org. phase composition as in Figure 2.

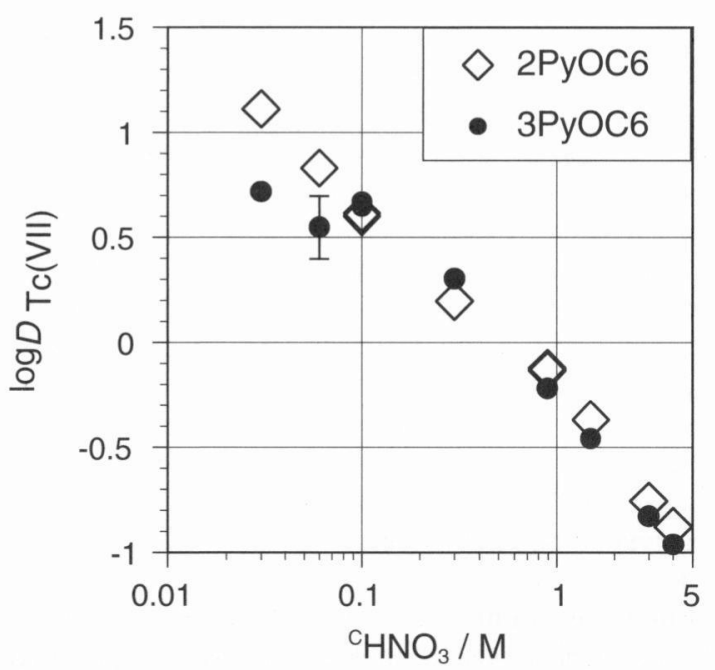

Figure 4. Effect of nitric acid concentration on the extraction of $\mathrm{Tc}(\mathrm{VII})$ at different positions of nitrogen in the substituent. Aq. and org. phase composition as in Figure 2. in these fully-substituted macrocycles, the protonation constants follow the order $2 \mathrm{Py}>3 \mathrm{Py}>4 \mathrm{Py}$, with possible stabilization due to intramolecular hydrogen bonding.

Calixarene size. Next, we compared the fully-substituted calix[n]arenes with $n=4,6$, or 8 in order to find an optimum extraction performance. In this series, 4,6 , or 8 pyridino groups respectively are attached to one molecular backbone with their nitrogen atoms in ortho position. The results are shown in Figure 5. Surprisingly, the ligands show a very similar behaviour, with the exception of the calix [8]arene at lower acidity. The latter is ascribed to the high molecular flexibility of this large macrocycle, which may hinder the intramolecular stabilization of the protonated form. However, above $0.1 \mathrm{M}$ $\mathrm{HNO}_{3}$ the differences between the three ligands level off and the values of $\log D$ decrease with the acid concentration linearly on a half-logarithmic scale. The question arises why does a compound with 4 ligating groups performs similar to its homologues containing 6 or 8 of these groups? We conclude that not all of the available nitrogen atoms in the larger calixarenes contribute to the anion binding. In other words, these ligand appear to represent not yet the optimum molecular structure to match the anion coordination sphere.

Acid competition. In the previous Figures the distribution coefficient decreased at higher acidity. In order to answer the question if this caused by the competitive extraction of nitrate or by the protonation of pertechnetate, we varied the composition of the aqueous phase. Figure 6 depicts the results. At constant

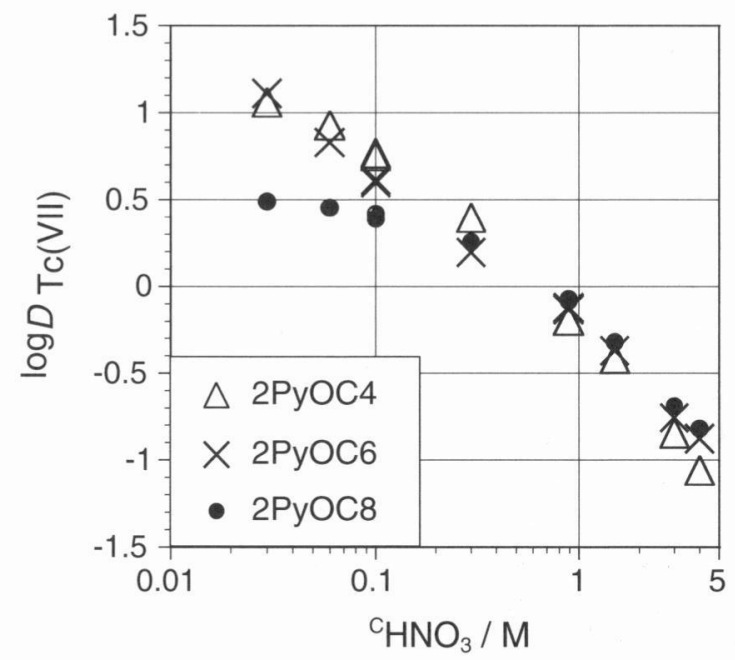

Figure 5. Comparison of calixarenes with different size. Aq. and org. phase as in Figure 2.

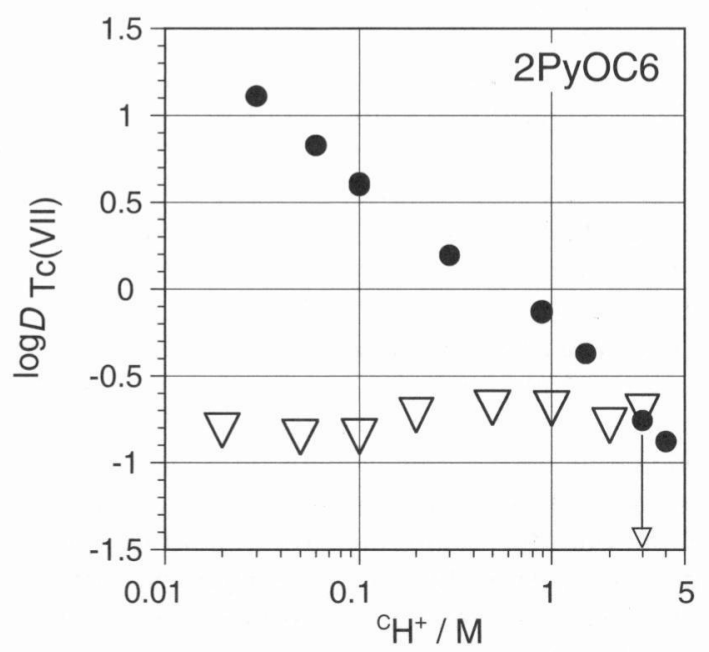

Figure 6. Effect of nitrate concentration on the extraction of $\mathrm{Tc}(\mathrm{VII})$ by 2 PyOC6. Aq. Phase: ${ }^{99} \mathrm{Tc}\left(\mathrm{TcO}_{4}^{-}\right) 0.05 \mathrm{mM}(3 \mathrm{kBq} / \mathrm{mL})$ in $\mathrm{HNO}_{3}$ $(0.03$ to $4 \mathrm{M}, \bullet)$, or in $\left[\mathrm{N}(\mathrm{Me})_{4} \mathrm{NO}_{3}+\mathrm{HNO}_{3}\right](3 \mathrm{M}$ nitrate, $\nabla)$; Org. Phase: $2 \mathrm{mM}$ extractant in $\mathrm{CHCl}_{3}$. 


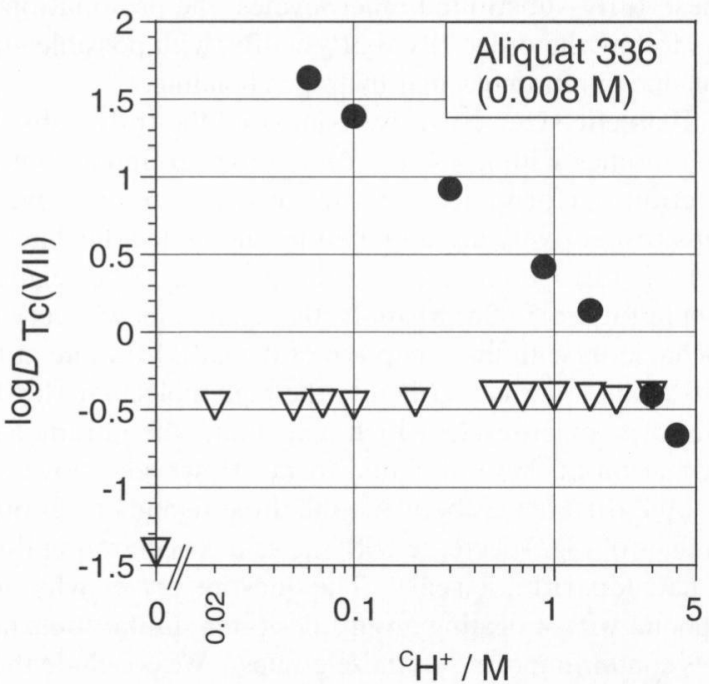

Figure 7. Comparison of the extraction by Aliquat-336 at varying and constant nitrate concentration. Aq. Phase as in Figure 6, Org. Phase: $8 \mathrm{mM}$ extractant in $\mathrm{CHCl}_{3}$.

nitrate concentration $(\mathrm{c}=3 \mathrm{M}), \log D$ of $\mathrm{Tc}(\mathrm{VII})$ remains constant within the error limits over a wide range of acid concentration. It shows that nitrate is extracted as competing anion. At the nitrate/pertechnetate concentration ratio of 60.000 in this series, $16 \%$ Tc are extracted. At a concentration ratio of 500 , $90 \%$ Tc is extracted. The selectivity is reasonable, but should be further improved in subsequent research works. The results also show that the protonation of $\mathrm{TcO}_{4}{ }^{-}$is of minor importance for amine-type extractants, in difference to solvating extactants such as TBP.

Similar experimental conditions were applied using Aliquat as extractant, because literature data for this extractant were reported only for varying ionic strength. As seen in Figure 7, the behaviour is very similar to that of calixarenes and shows that nitrate ions compete with pertechnetate ions. As the concentration of extractant in these series was four times higher than for calixarenes, the values of $\log D$ cannot be compared directly. However, by extrapolating literature data ${ }^{2}$ one can estimate that $D$ is about 3 times higher for fully-substituted calixarenes at given acid and ligand concentration. We therefore conclude macrocyclic effect in the extraction of pertechnetate by pyridino-substituted calixarenes. In comparison, the tertiary amine tri-n-dodecylamine $(0.008 \mathrm{M})$ in its protonated state extracts only $10 \% \mathrm{Tc}$ (VII) from $1 \mathrm{M} \mathrm{HNO}_{3}$, significantly less than pyridino- and quaternary amino-type ligands.

Does the extraction of $\mathrm{TcO}_{4}{ }^{-}$improve when smaller, less polarizable anions are present instead of nitrate? In order to answer this question, we subjected Tc(VII) to extraction from hydrochloric media by ortho-substituted calixarenes $2 \mathrm{PyOC} 4$ and 2PyOC6. Figure 8 shows the results. Indeed, $\log D$ increases by one order of magnitude when the aqueous phase contains $\mathrm{HCl}$ instead of $\mathrm{HNO}_{3}$. The order of anion interference agrees with the Hofmeister series. Another difference to the nitrate-containing system represents the protonation of 2PyOC4 which occurs below $0.1 \mathrm{M} \mathrm{HCl}$.

Quaternized nitrogen atoms. Does the extraction improves when the pyridino groups are quaternized? Figure 9 clearly demonstrates for nitrogen atoms in para position an efficient extraction from weakly acidic media by quaternized 4PyOC4Q. The extractants are in a cationic form already in this $\mathrm{pH}-$ range and therefore more effective than the protonizable ligands. At higher acidity, there are negligible differences in $\log D$ between protonated and quaternized calixarene. However, we noticed from a loss during synthesis work-up that the quaternized ligand 4PyOC4-Q is slightly soluble in water. This is attributed to the presence of four highly polar groups. In the di-substituted compound 4PyOC4Di-Q, the hydrophobic

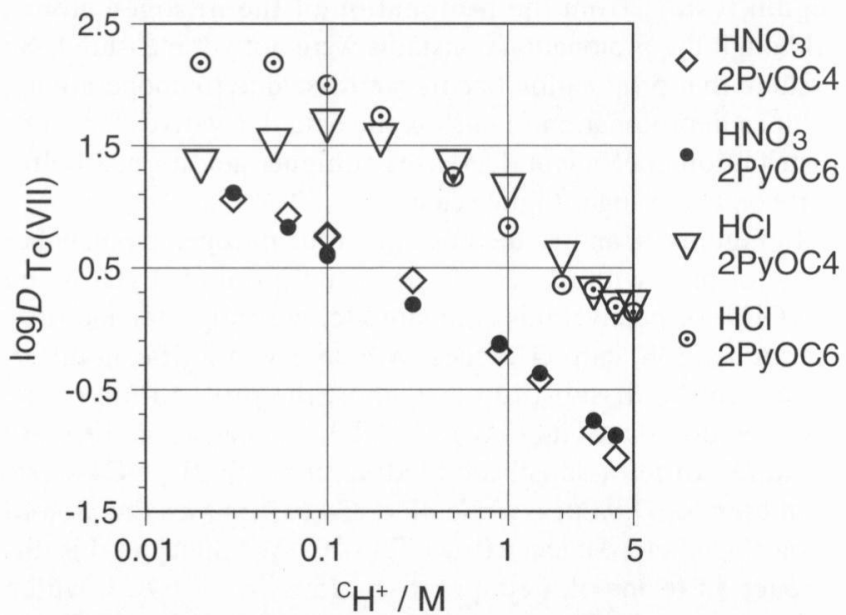

Figure 8. Anion competition in the extraction of Tc(VII). Aq. Phase: ${ }^{99} \mathrm{Tc}\left(\mathrm{TcO}_{4}{ }^{-}\right) 0.05 \mathrm{mM}(3 \mathrm{kBq} / \mathrm{mL})$ in $\mathrm{HNO}_{3}(0.03$ to $4 \mathrm{M})$; or $\mathrm{HCl}(0.03$ to $5 \mathrm{M})$; Org. Phase: $2 \mathrm{mM}$ extractant in $\mathrm{CHCl}_{3}$.

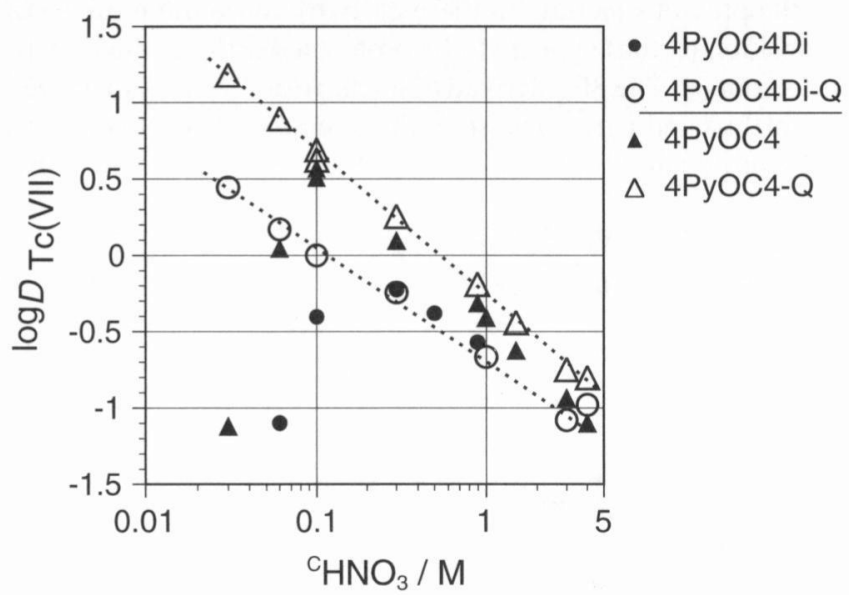

Figure 9. Comparison of protonated and quaternized nitrogen atoms and of the number of substituents per calix[4]arene. Aq. and org. phase composition as in Figure 2.

character dominates and it is not soluble in water.

\section{Conclusions}

It turned out that (i) the extraction improves with more pyridino groups per calixarene molecule; (ii) the number of substituents and the position of the nitrogen atom in the pyridine ring influence the ligand protonation and thus the extraction behaviour towards $\mathrm{Tc}(\mathrm{VII})$ at lower acid concentration which follows the order $2 \mathrm{Py}>3 \mathrm{Py}>4 \mathrm{Py}$; and (iii) molecular flexibility, cavity size and the number of pyridino groups in fully substituted calix $[n]$ arenes $(n=4,6,8)$ compensate each other which causes a similar extractability towards Tc(VII) among them.

By varying the composition of the aqueous phase, it was shown that nitrate competes with pertechnetate. The competition by chloride is weaker. Protonation of $\mathrm{TcO}_{4}{ }^{-}$contributed negligibly to the decrease of extraction up to $4 \mathrm{M}$ acid in the aqueous phase. Quaternized nitrogen is a better ligand than protonated one in weakly acidic media. A macrocyclic effect was observed. The binding is explained by electrostatic and hydrogen bonding interactions.

Acknowledgement. The authors thank Cognis, Mining- \& Ion-Transfer Chemicals Technology for a free sample of Aliquat336.

Financial support by the National Science Council/Fundamental Research Projects of Vietnam is appreciated. 


\section{Reference}

(1) R. Ludwig, T. K. D. Nguyen, and M. Nabeshima, Radiochim. Acta 89, 169 (2001).

(2) A. Landgren and J.-O. Liljenzin, Solv. Extr. Ion Exch. 17, 1387 (1999).

(3) A. Landgren, J.-O. Liljenzin, and M. Skalberg, Proceedings ISEC '96, ed. D. C. Shallcross, and R. Paimin, L. M. Prvcics (University of Melbourne, Australia), 1996, Vol. 2, pp. 1315-1320.

(4) V. K. Gupta, R. Ludwig, and S. Agarwal, Analyt. Chimica Acta 538 (1-2), 213 (2005).

(5)Z. Asfari, V. Böhmer, J. Harrowfield, and J. Vicens, eds. Calixarenes 2001 (Kluwer Acad. Publ., Dordrecht, 2001).

(6) M. Grunder, J.-F. Dozol, Z. Asfari, and J. Vicens, J. Radioanal. Nucl. Chem. 241, 59 (1999).

(7) M. Grunder, Doctoral Thesis, ULP-ECPM Strasbourg (2004).

(8) J. A. Gawenis, K. T. Holman, J. L. Atwood, and S. S. Jurisson, Inorg. Chem. 41, 6028 (2002).

(9) I. S. Antipin, S. E. Solovieva, I. I. Stoikov, and I. S.
Vershinina, et al., Russ. Chem. Bull. 53, 127 (2004).

(10) B. A. Moyer, P. V. Bonnesen, L. H. Delmau, T. J. Haverlock, K. Kavallieratos, and T. G. Levitskaia, Proceedings ISEC '02, ed. K. C. Sole, P. M. Cole, J. S. Preston, D. J. Robinsons, (C. v. Rensburg Publ. Ltd., South Africa 2002), pp. 299-306.

(11) K. Ohto, H. Higuchi, and K. Inoue, Solv. Extr. Research and Development, Jpn. 8, 37 (2001).

(12) F. Bottino, S. Pappalardo, and J. Inclusion, Phen. and Molec. Recognition 19, 85 (1994).

(13)F. Bottino, L. Giunta, and S. Pappalardo, J. Org. Chem. 54, 5407 (1989).

(14) S. Shinkai, K. Fujimoto, T. Otsuka, and H. L. Ammon, J. Org. Chem. 57, 1516 (1992).

(15) K. Belhamel, T. K. D. Nguyen, M. Benamor, and R. Ludwig, Eur. J. Inorg. Chem. 4110 (2003).

(16) F. Arnaud-Neu, G. Barrett, S. J. Harris, M. Owens, M. A. McKervey, M.-L. Schwing-Weill, and P. Schwinte, Inorg. Chem. 32, 2644 (1993).

(17)F. Arnaud-Neu, R. Ludwig, and T. K. D. Nguyen (unpublished results). 